\title{
Erratum to: A computerized analysis of femoral condyle radii in $A C L$ intact and contralateral ACL reconstructed knees using 3D CT
}

Rainer Siebold $\cdot$ Jeremie Axe $\cdot$ James J. Irrgang •

Kang Li $\cdot$ Scott Tashman $\cdot$ Freddie H. Fu

Published online: 17 February 2010

(C) Springer-Verlag 2010

Erratum to: Knee Surg Sports Traumatol Arthrosc

(2010) 18:26-31

DOI 10.1007/s00167-009-0969-8

Unfortunately, we misspelled the first name of the fourth author. The correct author name is Kang $\mathrm{Li}$ as now given above.

The online version of the original article can be found under doi:10.1007/s00167-009-0969-8.

R. Siebold ( $\square)$

Center for Knee and Foot Surgery,

Sports Traumatology, ATOS Hospital Heidelberg,

Bismarckstr. 9-15, 69115 Heidelberg, Germany

e-mail: rainer.siebold@atos.de

J. Axe

Department of Orthopaedic Surgery, Tufts Medical Center,

800 Washington Street, Boston, MA 02111, USA

J. J. Irrgang

Department of Orthopaedic Surgery, Clinical Research,

University of Pittsburgh, Centre for Sports Medicine,

3471 5th Avenue, Suite 1011, Pittsburgh, PA 15213, USA

K. Li $\cdot$ S. Tashman

Department of Orthopaedic Surgery,

Orthopaedic Biodynamics Laboratory,

University of Pittsburgh, Pittsburgh, PA 15230, USA

F. H. Fu

Department of Orthopaedic Surgery,

University of Pittsburgh, Division of Sports Medicine,

3471 5th Avenue, Suite 1011, Pittsburgh, PA 15213, USA 